\title{
Teachers Talk: Pressure Points in the K-8 Mathematics Curriculum
}

Kim Rheinlander

Dartmouth College, kimr@math.dartmouth.edu

Dorothy Wallace

Dartmouth College, dorothy.wallace@dartmouth.edu

Wells Morrison

Kimball Union Academy, bmorrison@kua.org

Daniel Ansari

University of Western Ontario, daniel.ansari@uwo.ca

Donna Coch

Dartmouth College, Donna.J.Coch@Dartmouth.edu

See next page for additional authors

Follow this and additional works at: https://digitalcommons.usf.edu/numeracy

Part of the Mathematics Commons

\section{Recommended Citation}

Rheinlander, Kim, Dorothy Wallace, Wells Morrison, Daniel Ansari, Donna Coch, and B. V. Williams.

"Teachers Talk: Pressure Points in the K-8 Mathematics Curriculum." Numeracy 1, Iss. 1 (2008): Article 4. DOI: http://dx.doi.org/10.5038/1936-4660.1.1.4 


\title{
Teachers Talk: Pressure Points in the K-8 Mathematics Curriculum
}

\begin{abstract}
Forty K-8 teachers participated in small, in-depth, facilitated discussions about "pressure points" in the curriculum. We define a pressure point as a topic, skill, or concept that is crucial to future mathematics learning but which many or most students do not master to the extent expected at a given grade level. They are issues that persist from one grade level to the next; eventually they impair the ability of students to succeed in technical disciplines. The teachers identified a number of pressure points; we focus on an understanding of place value and "reasonableness" of answer as two examples that were identified across all grade levels. Our small-scale study represents one approach to integrating teachers into the process of identifying important and relevant research questions in mathematics learning. We argue that the pressure points identified by teachers are areas in which targeted research would have maximum impact on learning and teaching, from teacher preparation to targeted diagnostic tools to student success rates.
\end{abstract}

Creative Commons License

(c) (1) (9)

This work is licensed under a Creative Commons Attribution-Noncommercial 4.0 License

Authors

Kim Rheinlander, Dorothy Wallace, Wells Morrison, Daniel Ansari, Donna Coch, and B. Venus Williams 
The Third International Mathematics and Science Study (TIMSS) shows a pattern of declining performance with respect to students from other countries as U.S. students progress through elementary and secondary education (National Center for Educational Statistics 1996, 1997, 1998). Curriculum content, the order of presentation and depth of coverage of topics, and the pedagogy associated with each topic have all been cited as points of difference between the U.S. math curriculum and the curricula of other, higher-scoring countries (Cogan and Schmidt 1999; Schmidt et al. 1996, 1997, 1999). The most recent TIMSS data, from 2003, provide little evidence of improvement: the U.S. ranked $12^{\text {th }}$ at grade four and declined to $15^{\text {th }}$ by grade eight. Indeed, the data from TIMMS indicate no significant overall improvement in U.S. math scores since 1995 (Mullis et al. 2004). Similarly data from the Program for International Student Assessment (PISA) 2003 show the U.S. ranking $24^{\text {th }}$ in both mathematical literacy and problem solving (Lemke et al. 2004). The National Assessment of Educational Progress (NAEP) provided confirmatory evidence, finding that only 36 percent of fourth graders and 30 percent of eighth graders were performing "at or above the proficient” level in 2005 (Perie 2005). According to Sanders (2004), since 1975 the U.S. has dropped from the rank of $3^{\text {rd }}$ to that of $17^{\text {th }}$ in terms of the percentage of students pursuing science and engineering, while the number of jobs in these fields is growing at more than three times the rate of other professions. This situation is clearly connected to mathematics performance, with nearly three fourths of U.S. post-secondary mathematics enrollments identified as remedial or introductory (Madison 2003).

Given these and other similar statistics and findings, it is crucial to identify what skills prove to be particularly challenging both for children to learn and for teachers to instruct. But mathematics education, even at the lower grade levels, involves a complex learning process including many different concepts, algorithms, and relationships, and it is not entirely clear what sort of mathematics education research will be of most benefit to classroom teachers. Here, we report the results of in-depth discussions with first to ninth grade teachers about what sorts of research would have the most practical value in their classrooms immediately. Because TIMSS and other studies report difficulties nationwide, the teachers were asked to think about how their students learn mathematics and what difficulties their students typically encounter in learning mathematics on a largescale, systemic level. Specifically, teachers were asked to identify "pressure points" in the K-8 curriculum. We defined a pressure point to be a topic, skill, or concept that many or most students do not master to the extent expected in a given grade, and that also is critical to future learning. That is, pressure points are bits of content in the curriculum for which a better understanding of how students learn would, in the teachers' views, drastically improve the number of students succeeding at that grade level and also have an impact on future learning of 
mathematics. Rather than address issues of standards (What should students know and be able to do at a given grade level?) we asked the teachers to draw upon years of experience in the classroom to describe their students' greatest difficulties. Teachers often possess understanding of student learning that is different from researchers' understanding; this paper presents one approach to integrating teachers into the process of identifying and defining research questions in mathematics learning that are particularly important to them.

In a review of research on teachers' decision making, Shavelson and Stern (1981) recommend that research on teaching should not merely make recommendations for practice, but should link those research recommendations to actual implementation in practice. With respect to questions of content, this kind of approach to mathematics research is reflected in the current study. Here, the crucial "link" is represented by a two-way conversation between researchers and practitioners, with the eventual goal of producing research findings and establishing new teaching practices that will link the two, reciprocally and iteratively. We also interpret the term "research recommendation" to be context dependent and, in particular, content dependent. Ball (2000) discusses the futility of separating issues of pedagogy from the content that it is supposed to address, citing three problems that need to be solved for any given piece of content: what teachers need to know, how they have to know it, and how they can be helped to learn to use it. To this we would add the importance of designing research that addresses those content issues that will have the most far-reaching impact on student learning. By our definition these pressure points are issues that defy the best intentions of knowledgeable and dedicated teachers, continue from one grade level to the next, and eventually impair the ability of students to succeed in technical disciplines.

Clearly, the decision about what content to spend time and energy on does not belong to the teacher alone. External pressures from administrators, parents, colleagues, standardized test scores, and textbook choices all affect how time is allocated in the classroom (Barr 1975; Floden et al. 1981, 1980; Shavelson and Stern 1981). Schwille, Porter, and Gant (1979) compiled an inventory of external pressures that might cause teachers to change the focus of the curriculum and noted that teachers seemed very willing to change the content of instruction, no matter which pressure was applied. A recent comparison of mathematics curriculum standards across states reveals, "a consistent lack of national consensus regarding common learning expectations in mathematics at particular grade levels” (Reys and Lappan 2007, 680). The multiplicity of forces at work here are consistent with Ball and Cohen's $(1996,6)$ finding that textbooks alone are "uneven" agents of curricular change. Considering both the central role of teachers in the classroom and their willingness to adjust (Schwille, Porter, and Gant, 1979), it is important to note that teachers will use "reliable information" to 
make important content decisions (Shavelson, Cadwell, and Izu, (1977, 95). Research that is targeted to the questions and issues of most concern to teachers of mathematics, as defined by teachers of mathematics, can be just such a reliable source of information.

Some researchers do attempt to address directly the kinds of knowledge about teaching that teachers themselves can provide (Cochran-Smith and Lytle 1990, 1993), considering the types of knowledge that teachers bring to their vocation in terms of practical knowledge of content, students, and pedagogical possibilities (Clandinin and Connelly 1987, 1991; Connelly and Clandinin 1985, 1988, 1990; Elbaz 1983, 1991). Some also consider the kind of knowledge arising from reflection on practice (Schon 1983, 1987, 1991). Although the programs of these researchers regard teachers as producing and possessing their own knowledge (Fenstermacher 1994, 13) in neither case do researchers attempt to mine the knowledge teachers might collectively hold on systemic issues. The assumption of many researchers seems to be that educational issues arise, are recognized, and are subsequently solved or not solved, strictly within the boundaries of the classroom and between the teacher and the students. In contrast, the teachers in the present study demonstrated that even with a wealth of knowledge and tools at their disposal, some learning goals - many that were tied to content spanning across grade levels-remained unmet. In this study we attempt to identify the parameters of a new content-based research targeting issues that cannot be addressed with known methods in a single classroom. The point of this paper is to use teachers' observations to identify pressure points in the curriculum where targeted research would have the most impact.

\section{Method}

We contacted the superintendents of 17 Supervisory Unions in Vermont and New Hampshire within a 50-mile radius of Dartmouth College. We described the nature of our project and asked for the superintendent's help in identifying teachers concerned with mathematics teaching who would be interested in joining a focus group to talk about the pressure points that they typically encounter with the students in their classrooms. Following this initial contact we mailed a written description of the project to the superintendents, who then shared the information with individual teachers, curriculum coordinators, or school principals within their districts. This procedure generated a group of 40 teacher participants representing six school districts in Vermont, two school districts in New Hampshire, two interstate districts and two private schools, one of which is the designated high school for public school students from several rural small towns 
that do not have high schools. The participants were equally divided between New Hampshire and Vermont.

There was wide variability in the wealth of the 10 districts represented, from those that receive significant state aid and contain schools in which $60 \%$ of the families have incomes below the federal poverty level to those with extensive resources and little poverty. Within the districts, the schools where participants taught were in rural towns with populations under 1,000; small towns with populations under 3,000; and a small city with a population of 13,000. The participants were all experienced teachers, with a range of 5-30 years in the classroom. Many of the participants had taught several grade levels.

During the Fall term of 2005 and the Winter term of 2006 we conducted five focus groups: Grades 1 and 2; Grade 4; Grade 5; Middle School (Grades 6, 7, 8); and Grade 9. Each session focused on a specific grade level but included teachers from the previous and following grades to provide additional reference points. Each teacher participated in only one session. The size of the sessions was kept small intentionally, to allow for deeper discussion, and varied from 7 to 11 participants. Teachers received a stipend of \$50.00 for attending the session and each district was compensated for a substitute in the participant's classroom. Breakfast and lunch were also provided to participants.

Each focus group ran from 8:00 am to 3:00 pm in a small conference room in a quiet area. The general format was a facilitated discussion, and all discussions were recorded on flip charts and documented by a scribe. Facilitators included two faculty members from the Department of Mathematics, a $5^{\text {th }}$-year mathematics graduate student and postdoctoral fellows from the Department of Psychological and Brain Sciences and the Department of Mathematics.

The morning session centered on identifying pressure points at the target grade level. First, teachers were asked to list all math topics covered in the target grade level. Of these, teachers identified the three that gave students the most difficulty. Most of the morning was devoted to discussions around these three topics with teachers giving in-depth examples of how they approached each one and attempting to identify exactly which aspects were the most troublesome for students. The last part of the morning was spent summarizing the discussion in preparation for the afternoon session.

After lunch, during the afternoon session, researchers from the department of Psychological and Brain Science and the Department of Education joined the group of teacher participants; the researchers were experienced in behavioral, developmental, and neuroscience research and had an interest in connecting empirical research with educational questions and practice. The morning's work was reviewed and presented, followed by a discussion with the scientists. The scientists were invited to suggest results from the research literature that might 
have bearing on the issues identified by the teachers and to discuss what kinds of new research would be useful to the teachers in addressing the issues raised.

The scientists played a number of roles in the afternoon sessions, among them participants in the ongoing discussion, experts in research, facilitators, and listeners. The scientists found that, although the teachers were unaware of some of the existing research literature that could be useful potentially, the teachers' questions and experiences often suggested new lines of research.

\section{Results}

Teachers were asked to discuss what is particularly difficult for their students. Predictably, the answers to this question were best understood in the context of the entire math curriculum because "difficult" topics are so only in relation to the rest of the subject matter. When asked to identify the big mathematical topics, concepts, and ideas that must be learned in the first and second grades, teachers from first, second, and third grade classrooms generated impressive lists highlighting the complexity of mathematics even at the elementary school level. In the following discussion we have resisted the urge to categorize and classify the teachers' responses, instead preferring to report what they saw in their own classrooms in their own words even preserving the granularity of the discussion.

Topics central to first grade included developing an understanding of the number system, ordering numbers, number sense, math facts to 10 , counting to 100, addition and subtraction of whole numbers, repeated operations, recognition of quantity, estimation, time (hour and half an hour), measurement (using nonstandard methods, as well as time, calendar, and money up to \$1.00), math language (addition, subtraction, plus, sum, equation, greater than, less than), fractions (1, 1/2, $1 / 4$ parts of the whole), geometry (solids, shapes, two and three dimensions, categorization), data collection (surveying, mapping), division, grouping, patterns of objects and numbers, and place value (ones and tens).

Teachers listed topics central to second grade mathematics as including counting by twos, fives, and tens; repeated addition; regrouping; fractions ( $1 / 3$, 1/8); measurement (time to 5-minute intervals, money to $\$ 5.00$ and making change); data interpretation and comparison; number grids; median and mode; patterns of numbers to 2,000; arrays; number sense; numbers and numerals; judging the "reasonableness" of an answer; language and memory (articulation, internalization, and retention); and problem solving and solution strategies expressed verbally.

Building on this list of mathematics curriculum content for the early elementary grades, teachers were asked to identify skills that were particularly difficult for second grade students. The pressure points for second graders- 
items that teachers felt students had particular difficulty with and presented particular stumbling blocks for future mathematics learning-were number sense, estimation, subtraction, the meaning and use of the equal sign, place value, understanding when an answer is reasonable, and moving from concrete to abstract reasoning (counting on fingers to solve a problem vs. adding groups). While we will not delve into the rich and varied meanings of some the terms used by teachers to identify pressure points, it is important to note that the use of a phrase such as "number sense" or "abstract" or "reasonable" depends at least in part on grade level for its meaning, a notion that we return to in the Discussion.

Third, fourth, and fifth grade teachers were similarly asked to provide a list of topics to be mastered in fourth grade. It is interesting to note the duplication of some topics from the previous list, presumably covered in greater depth in the later elementary grades: math facts (addition, subtraction, and multiplication, typically tested in the spring of fourth grade); addition and subtraction with twoand three-digit numbers; understanding zero; understanding place value to 100,000; multiplication; division (conceptualization and process, level of abstraction); fractions, decimals, percentages (new language and vocabulary); geometry: symmetry, angles, and classifying shapes, two and three dimensions, congruence, coordinates, and graphing; measurement: area, perimeter, value, money, and time; estimation; data collection; probability; number sense, particularly in terms of judging the reasonableness of problem solving methods and solutions; verbal expression of problem solving and solution strategies, written in sentences, algorithms, and equations; and a move from concrete to abstract thinking.

Identifying the fourth grade pressure points, teachers first noted that mastery of math facts for addition, subtraction, and multiplication is tested annually in the spring of fourth grade and therefore becomes a priority curricular challenge. Further, they noted that accuracy and speed (automaticity) in problem solving are goals. Aside from curricular demands, teachers indicated that place value is often not a secure concept in fourth grade. They also identified developing a number sense and a sense of the reasonableness of a solution, which may include an assessment of the potential for the answer to be correct, as pressure points. The teachers felt that students should have better mastery of basic problem-solving strategies together with the understanding that there are different ways to find a solution, as well as a better ability to generalize a problem or technique to a new situation. They once again mentioned the abstract nature of numbers, the transition from concrete to abstract, as well as "conservation of number."

The list of items to be covered in the fifth grade curriculum was truly huge: addition, subtraction, multiplication, and division especially when fractions, decimals and more than one-digit numbers are involved; problem solving and strategies for multi-step processes: order of operations, organization, identifying 
and extracting important information, testing hypotheses, making conclusions; estimation and rounding numbers; fractions: factors, proportionality, ratio, decimals, percentages, discounts, tax, least common denominator, equivalents; place value of decimals to the billions; measurements: types of triangles and angles, use of protractors and compasses, measuring 1/8 and 1/16 of an inch; conversion to the metric system; elapsed time; algebra: solving for the unknown variable; negative numbers; geometry: area, perimeter, volume of polygons and circles, classifying shapes, two and three dimensions, congruence, coordinates, graphing, angles, plotting points given with their coordinates, coordinate plane; number line; slope; negative numbers; patterns and rules; number series; probability; number sense; judging the reasonableness of problem-solving methods and solutions; language (articulation, internalization, retention); problem solving and ability to express solution strategies verbally in written sentences; algorithms; equations; concrete and abstract thinking; conceptual understanding of operations; and freedom and ease of playing with mathematical concepts.

Understandably, when asked to identify items presenting particular difficulties for students, the list for fifth grade was correspondingly longer: developing a number sense; reasonableness of the answers; fluency and ease with numbers; "numeracy;" the number line concept; having a solid ability to compute; conceptual understanding of operations; language issues; articulation, internalization, retention of math terms; basic problem solving strategies, especially with multi-step processes; understanding that there are different ways to find a solution; place value, addition, subtraction skills; mastery of math facts for addition, subtraction, multiplication; accuracy and speed in problem solving; generalizing a problem or a technique to a new situation; rounding and estimating; understanding decimals as well as division with a decimal or fraction and explaining the process with words; and multiplying fractions: what does $1 / 4$ of $1 / 2$ mean? The teachers also expressed frustration that the mathematics curriculum was too broad and the expectations for the pace of learning too fast in fifth grade, resulting in students who lack depth of knowledge and/or have not mastered essential fundamentals.

Nonetheless, during the middle school years the mathematics curriculum really takes off. Topics listed for grades 6-8 were: area and perimeter; prealgebra: linear equations with one variable; linear equations with two variables, solve for them, graph the solution; review of positive and negative numbers, multiplication, fractions; lots of word problems; probability; ratio; percent; proportion and scaling; introduction to algebra; graphing; geometry (similarity of forms); integers (operations with positive and negative numbers); mean, mode, median; rates of change; constant rate of change (slope); unit prices, that is, comparisons of two different numbers in the grocery store; combinations and permutations; place value (deeper understanding of "moving the decimal point"; 
need for working with other bases); number theory; algebra; concepts such as the Pythagorean theorem; growth; statistics; box and whisker plots as a way of looking at data; stem and leaf plotting: deeper interpretations of statistical data; miles per hour; rates; and percent change.

Teachers in these grades said that a basic, fundamental difficulty for them was that math is taught very differently from one school system to another. Students who change schools thus tend to have a difficult time, and, in these teachers' experiences, many children changed schools at least once during the middle school years. However, in spite of the huge array of topics to be addressed during these years, when asked for the greatest stumbling blocks for their students, a familiar list emerged: computation, word problems, reasonableness of answer, probability and statistics, geometry, fractions, division, place value, order of operations, integers, scaling, and use and understanding of math vocabulary.

In all, teachers mentioned 37 separate topics that they felt were especially difficult for students-that is, they identified 37 pressure points in K-8 mathematics learning. Of these, only four topics were mentioned in every single grade from first to eighth. These were place value, algorithms for processes and procedures, estimation, and reasonableness of answer. Below, we focus on place value and reasonableness of answer as two case study examples. The Appendix lists all of the topics mentioned by teachers as problem areas, in their own words, and a list of grades in which the topic was identified.

\section{Discussion}

What can we learn about mathematics learning and teaching from this gathering of experts? Certainly the discussions confirm that teachers of mathematics are required to address a broad range of topics in a single year, despite "a consistent lack of national consensus regarding common learning expectations in mathematics at particular grade levels” (Reys and Lappan 2007, 680). Indeed, the issues raised in these focus groups provide some justification for the recent attempt by the National Council of Teachers of Mathematics to focus learning goals more narrowly at each grade level (NCTM 2006). While there were many interesting strands within the teachers' discussions, perhaps the most provocative finding is that teachers were able to identify and agree upon pressure points in the K-8 mathematics curriculum: topics that students find particularly difficult to learn, are correspondingly difficult to teach, and which persist throughout the students' education.

It is interesting to compare the pressure points identified by teachers in this study with topics raised by Ball and Bass (2004) and quoted in Sanders (2004). 
Ball and Bass identified the mathematical ideas that are most important for teachers to know because they provide mathematical leverage for future knowledge. In comparison, the teachers in the present study identified the mathematical ideas that are most important because students have difficulty with them. Perhaps not surprisingly, the overlap in the basic topics identified between the studies is quite large. As did the teachers in this study, Ball and Bass specifically mentioned the concept of place value, common algorithms, and good sense about mathematical precision and estimation as some of the key topics and practices that provide mathematical leverage. This pattern suggests that teaching and learning of these particular topics, in terms of both teacher education and student education, are especially promising areas for future research.

\section{Place value}

In fact, the teachers identified the concepts of "place value" and recognizing and understanding the "reasonableness" of an answer as difficult at every levelfrom first to eighth grade. It was clear from the discussions that teachers used a wide variety of manipulative, interactive strategies for conveying the concept of place value to students, especially at lower grade levels. It was equally clear that these approaches did not automatically lead to facility with the algorithms of addition, subtraction, multiplication, and division, as these continued to be obstructions to progress at all grade levels.

Teachers at every grade level clearly had thought deeply about issues surrounding the teaching and understanding of place value, and posed a variety of insightful questions about place value, such as: When is it developmentally appropriate to begin the teaching of place value? Are we starting too early or too late? Should a variety of algorithms be accepted (such as for subtraction or division) so that students can choose the one that makes most sense to them? If so, will all the other options confuse them? And what will happen later when teachers expect everyone to follow a computation using the "standard" algorithm? Or what if the algorithm the student chooses is particularly slow, so that he or she is at a disadvantage when doing harder problems, especially on tests? And if only the standard procedure is taught, what happens to those who cannot make sense of it at the time?

These sorts of questions show that teachers believe that an understanding of place value develops and builds over many years. However, unlike some mathematical tasks (such as problem solving, where individual creativity may be the goal), place value is a social construction, being but one choice among many systems of numerals (Smith 1958, 23-77). Of all the possible number systems, this is the one used in western culture because of its economy of computation. As a cultural artifact, this number system has not only a cognitive aspect but also a communicative one. At some point we as a learning community not only share 
our number system, but we share certain algorithms for computing with it; otherwise we cannot communicate new knowledge to each other. The questions asked by the teachers in this study highlight the tension between these two needs. If the understanding of place value were merely a cognitive exercise, then teachers would be unconcerned about whether every student in a class had a different algorithm for division. But at some point in middle or high school, the standard algorithm is used as an explanation for other concepts and skills, like what to do with a decimal division problem or how to divide one polynomial by another. At that point the function of place value is communicative- the student is expected to know the basic concept and the form of the "standard" algorithm is used as syntax; in this case, in order to broaden the role of division, extending the range of things that can be divided by each other. So at every educational level, understanding place value is a crucial issue, but it might be so for very different reasons.

Are there answers to some of the teachers' questions about place value? Research on place value has shown that: (1) a robust understanding of the base-10 place value system of representation is of central importance to the bulk of mathematics education at all grade levels; (2) there are obstacles to both the learning and teaching of this system; and (3) there are particularly effective instructional approaches to teaching place value (and the processes relying on it).

When teachers used the term "place value," they referred not merely to students lacking a robust understanding of the base-10 place-value system, but to operations and representations which rely on it. In fact, a failure to acquire either procedural fluency or conceptual understanding of multidigit algorithms is often what brought to the teachers' attention this deficiency in understanding place value. Lacking a robust understanding of place value, students struggle to gain proficiency with multidigit calculation (Cauley 1988). Considered in this light, "place value" as a pressure point encompasses or strongly influences many common areas of challenge, including number sense, decimals and operations involving decimals, and scientific notation.

Impediments to learning place value can begin early, even as children learn to count and use small numbers. Griffin and Case (1997) showed that number sense, or a central conceptual structure for number, can be more rich and multifaceted than many parents and educators assume, but also that many young students who have not had experiences with number fail to develop a robust number sense. Number sense is a vital foundation for developing more complex number concepts such as place value (Case et al. 1994). Additionally, just as children begin using two- and three-digit numbers, the English number words themselves present learning obstacles due to their incongruity with the Arabic numerals (Fuson 1990; Gear, 2000). Geary (2000) concluded that "the most difficult quantitative concept that primary school children must learn is the base-10 
structure of the Arabic number system.” Concurring, the NCTM Standards (2000) and the National Research Council (Kilpatrick et al. 2001) both recognize the central importance of place value in mathematics education and emphasize the need for place value to be taught with a focus on conceptual understanding. Unfortunately, traditionally, mathematics schooling in the United States has emphasized memorization of multidigit calculation procedures, which has been shown to be less effective than teaching for understanding (Fuson et al. 1997; Hiebert and Wearne 1996). This may be compounded by teachers' lack of understanding and confidence (Stacey et al. 2001).

An example of a successful effort to overcome these obstacles in K-2 is Number Worlds (http://clarku.edu/numberworlds/) (Griffin 2004), a curriculum that focuses on building strong cognitive associations among number words, Arabic numerals, the physical quantities they represent, and common schematic representations of number (such as a number line, a clock, and a thermometer). It emphasizes conceptual understanding along with procedural fluency, and provides opportunities for hands-on exploration, problem solving, and communication. This approach is consistent with a report from the National Research Council (Kilpatrick et al. 2001, 198) noting that effective instructional approaches to multidigit arithmetic share some key features including that "instructional supports (classroom discussions, physical materials, etc.) are available to focus the students' attention on the base-10 structure of the number system and on how that structure is used in the algorithm." Several successful research-based programs for teaching multidigit arithmetic with understanding exist, and tend to share features with Number Worlds-in particular the problemsolving approach and sharing of explanations (Fuson et al.1997).

Despite these findings from the extant research literature, further research is needed that appreciates the multiple roles played by the seductively simple term "place value" and helps educators, especially administrators and textbook writers, to understand how these roles develop at different levels. Given the questions that these teachers posed, translation from research to practice-and from practice to research-is clearly not happening effectively in the case of place value.

\section{Reasonableness of answer}

The topic of place value stands in interesting contrast to another repeated theme and pressure point: the ability to recognize and judge the "reasonableness" of an answer. Again, teachers at every level identified this issue as a difficult thing for their students to grasp. The basic issue as discussed by the teachers in each group was that students at a given level could not recognize an answer as wrong that their teacher could see was obviously wrong and which the students (at least theoretically) also had the available tools to see was obviously wrong. For the different grade levels, these tools ranged from familiarity with numbers of a 
certain type or size to estimation skills to basic arithmetic coupled with logic. In situations involving reasonableness of an answer, unlike in the example of place value, teachers seemed unconcerned with what method was brought to bear on a problem. In fact, the teachers noted that no single method would suffice for all problems - there is no "standard algorithm" for reasonableness of answer. It was unclear from the discussion whether students were unable to carry out the necessary checks on an answer or whether they were just not inclined to think about the reasonableness of an answer; the teachers speculated that both processes might be involved, separately or together, at different times. Interestingly, if the crucial piece is a question of the habit of thinking about whether an answer is reasonable or not, then that habit was missing across all levels from first through eighth grade.

While the source of the problem in developing skills and knowledge related to recognizing the reasonableness of an answer was unclear, what to do about this problem was even less clear. The teachers noted that some kind of diagnostic test related to this pressure point would be very useful. Again, the teachers posed many questions that could lead to targeted research and development of assessments and interventions: If a student can't tell when an answer is reasonable, is it because the student doesn't think to check? Or perhaps his or her arithmetic skills aren't strong enough? Or is it that the student doesn't understand how to estimate? Or does the student know these separate things but not how to transfer them to the problem at hand? Without knowing which of these potential problems exist, it is difficult to know what to do to improve student performance on this topic/skill/habit.

Interestingly, this phenomenon, which was identified readily and pervasively by teachers across grade levels, is not easy to identify as a subject of existing research. However, much has been published about related topics such as: (1) estimation, and (2) students' beliefs and attitudes about math, both of which may shed light on the reasonableness of answer issue.

Research shows that students' performance on numerical estimation tasks is surprisingly poor, and can lag well behind their ability to perform exact calculations in the same range (Dwoker 1997). Moreover, computational estimation improves so gradually that some studies have not been able to find improvement over one or two years (Schoen et al. 1981). Difficulties with estimation are prevalent in educational systems across countries, including Japan, France, Britain, and Canada.

Despite this, requiring students to engage in estimation exercises along with exact calculations has often been encouraged (NCTM 2000) under the assumption that it will lead to enhanced number sense and contribute to sense making of exact calculations. However, it may be that in fact a stronger number sense is needed in order to support strong estimation skills. Siegler and Booth $(2005,211)$ have 
suggested that one "source of the slow and incomplete development of estimation skills [is] non-linear representations of numerical magnitudes.” When asked to place the numbers 1-100 on a number line, many kindergartners and first graders place the numbers logarithmically, shifting and compressing numbers to the right rather than producing a linear distribution. Many children up to fourth grade will do the same for the numbers 1-1000, even after they have begun to represent 1100 linearly. These findings suggest that within the range in which students greatly compress numbers, their representations of these magnitudes are largely indistinguishable, and therefore the students are unlikely to have a strong ability to detect an unreasonable estimate. There is support (Rittle-Johnson et al. 2001) for Siegler and Booth's (2005, 211) suggestion that "helping children develop linear representations of a wide range of numerical magnitudes may be a key step in allowing development of estimation to proceed more rapidly.”

Also of concern to both educators and researchers, and perhaps closely related to this pressure point, is the finding that many students find math to be about memorization of rules (Kilpatrick et al. 2001) and to be without concrete grounding, lacking relevance or connection to physical reality. That is, they find numbers, mathematical processes, and solutions to be abstract. Moreover, they often have low confidence in their own ability, and lack ways to assure themselves that their own work makes sense (Butterwoth 1999). Certainly students in this frame of mind, with these beliefs about mathematics, would be at risk for failing to notice unreasonable answers.

Intriguing research on how brain systems support concepts of quantity and number may also shed light on why students struggle with reasonableness of answer. Combined results from a range of brain sciences provide evidence (Feigenson et al. 2004) that humans posses two core systems: one which allows for approximate representations of magnitude (something like a "mental number line”) and another which allows for precise representations of distinct individuals. Indeed, studies have shown that different regions of the brain are utilized when performing exact calculations as compared to approximate-magnitude judgments (Dehaene et al. 2003). Exact calculations may make more use of the precise core system as well as language areas, and magnitude estimation may make more use of the "mental number line" system and visuospatial regions. Importantly, neither system supports more complex concepts such as square roots, fractions, negative numbers, or even exact integers. Moreover, how these two (or more) core systems work together to produce mathematical intuition is not known. However, it is believed that while deploying our core systems individually is automatic (and "effortless"), reconciling the multiple representations and building on them to support more complex mathematical concepts takes real effort, time, and learning. 


\section{Recommendations}

One of the most striking aspects about the pressure points identified by the teachers in this study is the extent to which many of the same topics reoccur across grade levels. This pattern is likely related to the observation that U.S. students tend to fall increasingly further behind their international peers as they pass through the U.S. educational system (National Center for Educational Statistics 1996, 1997, 1998; Sanders 2004). Considering just the two repeated themes discussed at length above, place value and reasonableness of answer, it seems relatively clear that a lack of understanding of either or both of these concepts would be enough to derail a student's progress in math or science starting in elementary school but extending to high school and beyond.

This small-scale study was a first attempt to model a methodology for integrating teachers into the process of defining research questions in mathematics learning. Our findings suggest several recommendations for the mathematicseducation, educational-research, and education-policy communities:

1. Prioritize research on the pressure points identified by teachers so as to maximize the impact of research on student success rates. In particular we need to know whether the specific content identified in this study is representative of the national picture.

2. Tackle the pressure points separately, as each one represents a different kind of knowledge that may be best acquired in a particular way at a particular point in a student's education.

3. Treat pressure points that are common to all levels as a systemic problem that should be researched and solved as such, rather than as a concept addressed at a single point of contact with a particular teacher.

4. Develop an awareness of the critical nature of these topics in teacher preparation and professional development programs.

Teachers intend to help students master a subject in both variety and depth, with scores on standardized tests in many cases a consideration forced upon them (Stake 2002). Both researchers and teachers apparently agree that the content of the K-12 mathematics curriculum is rich, varied, and too interrelated to be represented by a single test score (Niss 1999; Stake 2002). Most test items are chosen to distinguish between students with high and low aptitudes, not because they indicate content that is necessary for the student's progress. Teachers know that they cannot use scores on such tests as diagnostic tools (Niss 1999; Stake 2002). Teachers in this study repeatedly requested that research be conducted that would provide useful diagnostic tools for students having difficulty with particular concepts. By identifying the pressure points in the K-8 mathematics 
curriculum as perceived by teachers, we hope to have provided guidelines for future research in mathematics education that will link back to implementation and practice, and then contribute to further research, in an iterative process consistent with a science-of-learning approach to evidence-based, optimal mathematics education at all grade levels.

\section{Acknowledgments}

This research was in part supported by funds from an NSF Science of Learning Center Grant supporting the creation of the Center for Cognitive and Educational Neuroscience (CCEN) at Dartmouth College (SBE-0354400, Michael Gazzaniga, PI). We would like to thank the teachers who so willingly participated for their time and insight. We would also like to thank the four reviewers for their helpful comments.

\section{References}

Ball, D. L. 2000. Bridging practices: Intertwining content and pedagogy in teaching and learning to teach. Journal of Teacher Education 51(3): 241-247. http://dx.doi.org/ 10.1177/0022487100051003013

— need to know? Paper presentation at a conference sponsored by the Education Policy Center at Michigan State University, Washington D. C., http://wwwpersonal.umich.edu/ dball/presentations/index.html

— curriculum materials in teacher learning and instructional reform? Educational Researcher 25(9): 6-8, 14. http://dx.doi.org/10.2307/1177151

Barr, R. 1975. How children are taught to read: Grouping and pacing. School Review 83: 479-498. http://dx.doi.org/10.1086/443205

Butterworth, B. 1999. The Mathematical Brain. London: Macmillan Publishers.

Cauley, K.M. 1988. Construction of logical knowledge: Study of borrowing in subtraction. Journal of Educational Psychology 80: 202-205. http://dx.doi.org/ 10.1037/0022-0663.80.2.202

Clandinin, D. J., and F.M. Connelly. 1987. Teachers' personal knowledge: What counts as personal in studies of the personal. Journal of Curriculum Studies 19: 487-500. http://dx.doi.org/10.1080/0022027870190602

- 1991. Narrative and story in practice and research. In The reflective turn: Case studies in and on educational practice, ed. D. Schon 258-281. New York: Teachers College Press.

Cochran-Smith, M., and S. Lytle. 1990. Research on teaching and teacher research: The issues that divide. Educational Researcher 19(2): 2-11. http://dx.doi.org/ $\underline{10.2307 / 1176596}$ 
. 1993. Inside outside: Teacher research and knowledge. New York: Teachers College Press.

Cogan, L. S., and W.H. Schmidt. 1999. Middle school math reform. Middle Matters 8 (Fall): 2-3.

Connelly, F. M., and D.J. Clandinin. 1985. Personal practical knowledge and the modes of knowing: Relevance for teaching and learning. In Learning and teaching the ways of knowing, ed. E. Eisner, 174-178. Chicago: University of Chicago Press.

- 1988. Teachers as curriculum planners. New York: Teachers College Press.

- 1990. Stories of experience and narrative inquiry. Educational Researcher 19(5): 2-14. http://dx.doi.org/10.2307/1176100

Dehaene, S., M. Piazza, P. Pinel, and L. Cohen. 2003. Three parietal circuits for number processing. Cognitive Neuropsychology 20 (3/4/5/6): 487-506.

Dwoker, A. 1997. Young children's addition estimates. Mathematical Cognition 3: 141154.

Elbaz, F. L. 1983. Teacher thinking: A study of practical knowledge. London: Croom Helm.

- 1991. Research on teacher's knowledge: The evolution of a discourse. Journal of Curriculum Studies, 23: 1-19. http://dx.doi.org/10.1080/0022027910230101

Feigenson, L., S. Dehaene, and E. Spelke. 2004. Core systems of number. TRENDS in Cognitive Sciences, Vol.8 No.7.

Fenstermacher, G. D. 1994. The knower and the known: The nature of knowledge in research on teaching. Review of Research in Education 20: 3-56. http://dx.doi.org/ $10.2307 / 1167381$

Floden, R.E., A.C. Porter, W.H. Schmidt, D.J. Freeman, and J.R. Schwille. 1981. Responses to curriculum pressures: A policy capturing study of teacher decisions about content. Journal of Educational Psychology 73: 129-141. Also Research Series No. 74, East Lansing: Michigan State University, Institute for Research on Teaching, 1980.

Fuson, K.C. 1990. Conceptual structures for multiunit numbers: Implications for learning and teaching multidigit addition, subtraction, and place value. Cognition and Instruction 7: 343-403. http://dx.doi.org/10.1207/s1532690xci0704_4

—., D. Wearne, J.C. Hiebert, H.G. Murray, P.G. Human, A.I. Olivier, T.P. Carpenter, and E. Fennema, E. 1997. Children’s conceptual structures for multidigit numbers and methods of multidigit addition and subtraction. Journal for Research in Mathematics Education 28: 130-162. http://dx.doi.org/10.2307/749759

Geary, D.C. 2000. From infancy to adulthood: the development of numerical abilities. European Child and Adolescent Psychiatry 9: 11/11-11/16.

Griffin, S. 2004. Building number sense with Number Worlds: a mathematics program for young children. Early Childhood Research Quarterly 19: 173-180. http://dx.doi.org/10.1016/j.ecresq.2004.01.012

—, and R. Case. 1997. Rethinking the primary school math curriculum: An approach based on cognitive sciences. Issues in Education 3: 1-49.

— , R. Case, and R. Siegler. 1994. Rightstart: Providing the central conceptual prerequisites for first formal learning of arithmetic to students at-risk for school 
failure. In Classroom lessons; Integrating cognitive theory and classroom practice, ed. K. McGilly, 24-49. Cambridge, MA; Bradford Books MIT Press.

Hiebert, J. and D. Wearne, D. 1996. Instruction, understanding and skill in multidigit addition and subtraction. Cognition and Instruction 14: 251-83. http://dx.doi.org/ 10.1207/s1532690xci1403_1

Kilpatrick. J., J. Swafford, and B. Findell, B., eds. 2001. Adding it up: Helping Children Learn Mathematics. National Research Council, Mathematics Learning Study Committee. Center for Education, Division of Behavioral and Social Sciences and Education. Washington, DC: National Academy Press.

Lemke, M., A. Sen, E. Pahlke, L. Partelow, D. Miller, T.Williams, D. Kastberg, and L. Jocelyn. 2004. International Outcomes of Learning in Mathematics Literacy and Problem Solving: PISA 2003 Results From the U.S. Perspective. Education Statistics Quarterly, Vol.6, Issue 4, http://nces.ed.gov/programs/quarterly/vol_6/ 6 4/2 2.asp

Madison, B.L. 2003. Articulation and quantitative literacy: a view from inside mathematics. In Quantitative literacy: Why Numeracy Matters for Schools and Colleges, ed. B.L. Madison and L.A. Steen, 153-164. National Council on Education and the Disciplines, http://www.maa.org/QL/pgs153_164.pdf.

Mullis, I.V.S., M.O. Martin, E.J. Gonzalez, and S.J. Chrostowski. 2004. Findings From IEA's Trends in International Mathematics and Science Study at the Fourth and Eighth Grades. Chestnut Hill, MA: TIMSS and PIRLS International Study Center, Boston College.

National Center for Education Statistics. 1996. Pursuing excellence: a study of U.S. eighth-grade mathematics and science teaching, learning, curriculum, and achievement in international context (NCES 97-198). Washington, D.C.: NCES.

- 1997. Pursuing excellence: a study of U.S. fourth-grade mathematics and science achievement in international context (NCES 97-255). Washington, D.C.: NCES.

- 1998. Pursuing excellence: a study of U.S. twelfth-grade mathematics and science achievement in international context (NCES 98-049). Washington, D.C.: NCES.

National Council of Teachers of Mathematics. 2000. Principles and standards for school mathematics. Reston, VA: National Council of Teachers of Mathematics.

2006. Curriculum Focal Points for Prekindergarten through Grade 8 Mathematics, http://www.nctm.org/standards/default.aspx?id=58

Niss, M. 1999. Aspects of the nature and state of research in mathematics education. Educational Studies in Mathematics, 40, 1-24. http://dx.doi.org/10.1023/ A:1003715913784

Perie, M., W. Grigg, and G. Dion. 2005. The Nation's Report Card: Mathematics 2005 (NCES 2006-453). U.S. Department of Education, National Center for Education Statistics. Washington, D.C.: U.S. Government Printing Office.

Reys, B and G. Lappan. 2007. Consensus or confusion? The intended math curriculum in state-level standards. Phi Delta Kappan (May): 676-680. 
Rittle-Johnson, B., R.S. Siegler, and M.W. Alibali. 2001. Developing conceptual understanding and procedural skill in mathematics: an iterative process. Journal of Educational Psychology, 93: 346-362. http://dx.doi.org/10.1037/0022-0663.93.2.346

Sanders, T. 2004. No time to waste: the vital role of college and university leaders in improving science and mathematics education. Presentation at Teacher Preparation and Institutions of Higher Education: Mathematics and Science Content Knowledge, U. S. Department of Education, http://www.teacherssupportnetwork.com/corporate/ TedSanders.pdf.

Schmidt, W.H., D. Jorde, L.S. Cogan, E. Barrier, I. Gonzalo, U. Moser, K. Shimizu, T. Sawada, G.A. Valverde, C. McKnight, R.S. Prawat, D.E. Wiley, and S.A. Raizen. 1996. Characterizing pedagogical flow: An investigation of mathematics and science teaching in six countries. Dordrecht, Netherlands: Kluwer.

Schmidt, W.H., C.C. McKnight, L.S. Cogan, P.M. Jakwerth, and R.T. Houang. 1999. Facing the consequences: using TIMSS for a closer look at U.S. mathematics and science education. Dordrecht, Netherlands: Kluwer.

Schmidt, W.H., C.C. McKnight, and S.A. Raizen. 1997. A splintered vision: an investigation of U.S. science and mathematics education. Dordrecht, Netherlands: Kluwer.

Schoen, H. L., C.D. Freison, J.A. Jarrett, and T.D. Urbatsch. 1981. Instruction in estimating solutions of whole number computations. Journal for Research in Mathematics Education, 13: 211-232.

Schwille, J., A. Porter, and M. Gant. 1979. Content decision-making and the politics of education (Research Series No. 52). East Lansing: Institute for Research on Teaching, Michigan State University.

Shavelson, R.J., J. Cadwell, and T. Izu. 1977. Teachers' sensitivity to the reliability of information in making pedagogical decisions. American Educational Research Journal, 14: 83-97.

Shavelson, R.J., and P. Stern. 1981. Research on teachers' pedagogical thoughts, judgments, decisions, and behavior. Review of Educational Research, 51(4): 455498.

Siegler, R., and J. Booth. 2005. Development of numerical estimation, A review. In Handbook of Mathematical Cognition, ed. J.I.D. Campbell 197-212. New York: Psychology Press.

Smith, D. E. 1958. History of Mathematics, Vol. 2. New York: Dover

Stacey, K., S. Helme, V. Steinle, A. Baturo, K. Irwin, and J. Bana, J. 2001. Preservice teachers' knowledge of difficulties in decimal numeration. Journal of Mathematics Teacher Education 4: 205-225 http://dx.doi.org/10.1023/A:1011463205491

Stake, R. 2002. Teachers conceptualizing student achievement. Teachers and Teaching: Theory and Practice 8(3/4): 303-312. 


\section{Appendix}

$\underline{\text { Topic }}$

Grade where the issue is of concern

Mathematics

Equal sign....................................................................................1,2,3

Subtraction (as the reverse of addition) ................................................1,2,3

Concrete to abstract reasoning $\quad 1,2,3,4$

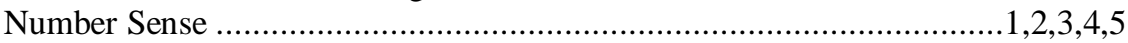

Place Value ..................................................................................1,2,3,4,5,6,7,8

Algorithms for processes and procedures.........................................1,2,3 .............. 9,10,11,12

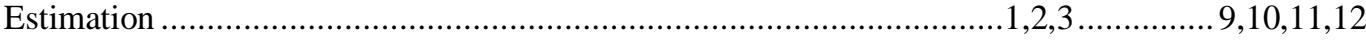

Reasonableness of Answer ............................................................1,2,3,4,5,6,7,8, 9,10,11,12

Base 10 and beyond (working in other bases) ………................................... 4

Conservation of Numbers.....................................................................

Mastery of Math Facts ...................................................................................

Parts to Whole

Automaticity (accuracy and speed) with math facts .....................................4,5

Generalizing a process or procedure to a new situation ..................................4,5

Problem-solving Strategies (esp. with multi-step processes)...........................4,5

Language and Literacy (vocabulary, speaking, writing) ................................4,5,6,7,8, 9,10,11,12

Conceptual Understanding of Operations ..........................................................5

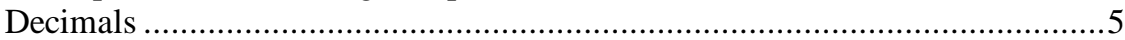

Number Line .............................................................................................

Numeracy (fluency and ease with numbers) .................................................

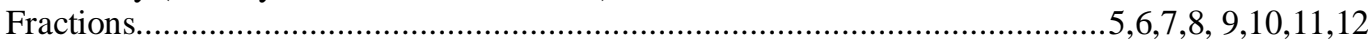

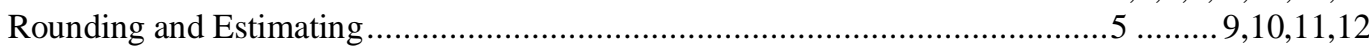

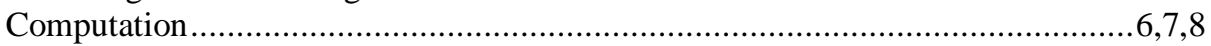

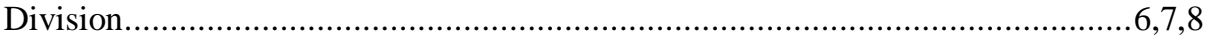

Probability and Statistics.......................................................................6,7,8

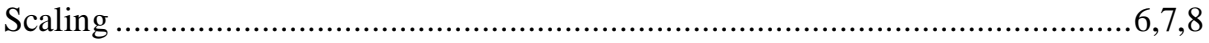

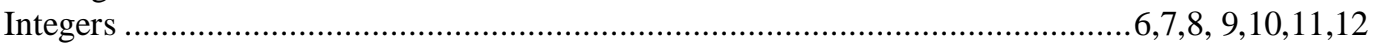

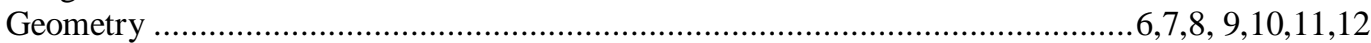

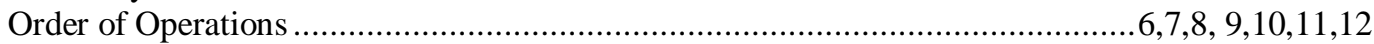

Word Problems....................................................................................6,7,8, 9,10,11,12

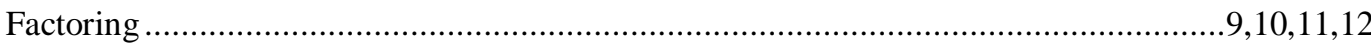

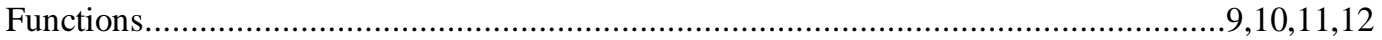

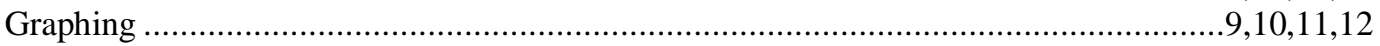

Real-life Applications ....................................................................................10,11,12

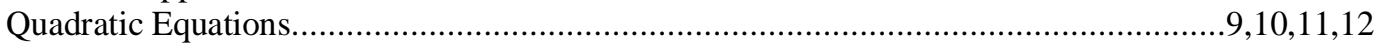

Scientific Notation …….............................................................................9,10,11,12

Signed Numbers ……................................................................................9,10,11,12 